\title{
Retrospective Evaluation of Variations in Root Canal Morphology of Permanent Maxillary Premolars Among the Emirate Population
}

Hajir S.Y. Alnaqbi ( $\sim$ Hajir-binyarouf@hotmail.com )

University of Sharjah

Mehmet Omer Gorduysus

University of Sharjah

Saaid Al Shehadat

University of Sharjah

Saad Wahbi Al Bayatti

University of Sharjah

Ibrahim Mahmoud

University of Sharjah

\section{Research Article}

Keywords: canal configuration, pulp chamber, root number, root canal, UAE

Posted Date: December 10th, 2021

DOI: https://doi.org/10.21203/rs.3.rs-1148732/v1

License: (c) (i) This work is licensed under a Creative Commons Attribution 4.0 International License.

Read Full License 


\section{Abstract}

Background: This research aims to identify the most common morphology of the upper premolars in a group of local and nonlocal people in the UAE using cone-beam computed tomography (CBCT).

Methods: CBCT images of a total of 214 intact maxillary premolars were analysed with 3D reconstruction GALAXIS viewer software. The Pearson Chi squared test and the two samples $t$ test were applied.

Results: In all, $90 \%$ of the maxillary first premolars had two roots ( $92 \%$ females, $88 \%$ males, $83 \%$ locals, $96 \%$ nonlocals). A total of $52 \%$ of maxillary second premolars had two roots ( $47 \%$ females, $56 \%$ males, $38 \%$ locals, $67 \%$ nonlocals). Two cases had three roots among local males. A significant difference of one root in the maxillary second premolar was observed between locals $(63 \%)$ and nonlocals (33\%), while two roots were higher among nonlocals $(67 \%)$ than locals $(37 \%, p=0.002)$. Three roots were discovered in two teeth of the local UAE first premolar. The most common canal morphology in the maxillary first premolar group among local UAE subjects was type $\mathrm{V}(52 \%)$, and among nonlocal UAE subjects was type $\checkmark(59 \%)$. Additional types included 7 (13.2\%) identified and unrelated to the Vertucci classification. The dominant canal morphology in the maxillary second premolar among local UAE subjects was type II (32\%), and among nonlocal UAE subjects was type V (25\%); among the additional types, 12 (23.1\%) were identified and not related to the Vertucci classification. There was a significant difference in the distance from the pulp chamber roof to the cementoenamel junction (CEJ) and the measurement between the single-rooted maxillary premolar CBCT for local UAE subjects was $1.36 \mathrm{~mm}(\mathrm{SD} \pm 0.75)$ and for nonlocal subjects was $1 \mathrm{~mm}$ (SD $\pm 0.27, p=0.049)$. There were statistically significant differences in all measurements between multiple rooted maxillary premolar CBCTs for local UAE and South Asian subjects $(p<0.05)$

Conclusions: The results suggest a more quantitative approach to maxillary first and second premolar access cavity preparation in the UAE population to prevent errors and iatrogenic damage when identifying the canals; using CBCT measurements for more precise access preparations may be advantageous.

\section{Background}

Endodontology addresses the dental pulp and periradicular area in healthy, diseased, injured situations and encompasses how it functions, prevention and treatment [1]. The most frequent reason for endodontic treatment failure is a misunderstanding of tooth anatomy and technical competence [2]. As a result, a thorough knowledge of pulp canal anatomy is critical for a successful root canal treatment (RCT) $[3,4]$. Additionally, the dentist must be armed with the creative skills of reading an X-ray and must examine the dental pulp and periapical tissue to reach the correct diagnosis [5]. The initial stage in pulp canal therapy is to obtain access to hollow space preparation. The subsequent steps and the result will preserve the tooth structure as much as possible [6]. The tooth anatomy varies between populations, persons, and races; trouble is also faced when studying root canal morphology [7-10]. Most of the variation is seen in maxillary first and second bicuspid teeth [11-13]. The anatomy of the premolar teeth 
is complex and is an enigma $[3,14,15]$. Even so, the bicuspid's maxillary tooth has an oval-shaped canal. It has more than one canal, but the maxillary premolars generally have roots correlated with the number of root canals [3]. In most cases, many premolar teeth have extra roots and extra canals.

Therefore, many modifications have been made to classify root canal configuration systems in recent studies [16]. The most common one was the Vertucci classifications. Vertucci has categorised root canal morphology into eight distinct categories $[9,17]$. Some research findings in the literature are consistent with previous investigations by Vertucci et al. (2005). Other study findings contradict previous research by Vertucci et al. (2005) [18]. Unfortunately, many investigations utilising various methods have shown significant differences in assessing the root canal anatomy of maxillary premolars across different cultures $[13,17,19]$. The success rate based on utilising the present technique to confront the challenge during root canal treatment lowers root canal treatment failure. A periapical radiograph has traditionally been used to visualise the dentition into 2D images for root canal treatment [20]. Recently, CBCT has made it possible to visualise the dentition and surrounding structures in the anatomical 3D space into 3D images [21]. CBCT is a basic image to demonstrate and assess root canal morphology for a given population [22]. This study further investigates the location of the canal orifices, dimensions of the pulp chamber and variations in the number of roots and canals for the upper first and second premolars due to their challenging morphology in clinical endodontics. The majority of research has found substantial differences in the root canal morphology of maxillary premolars among populations. However, there are no published studies with detailed data on the root canal anatomy of the maxillary first and second premolars in the UAE population. Thus, the purpose of this research was to examine the root canal architecture of maxillary first and second premolars in the UAE population and compare the results to previous studies in other populations.

\section{Methods}

\section{Sample collection}

From 2015 to December 2020, researchers from University Dental Hospital Sharjah performed a retrospective study. CBCT scans from patients who came to UDHS for different reasons were examined. CBCT scans of maxillary first and second premolars were examined for this research. The UDHS institutional review board granted ethical clearance (REC-20-03-03-01-S). The radiology archives of the hospital were used to acquire all of the scans. Sampling was performed at random, and the sample size was calculated using a previous study [23] with a confidence level of $95 \%$. The sample size for maxillary first premolars was 88 , while the sample size for maxillary second premolars was 98 . We needed 107 maxillary first premolars and 108 maxillary second premolars to adjust for observational error.

$\mathrm{CBCT}$ images were obtained using the radiograph Sirona Galileos. 3D reconstruction was performed using Galaxix (Sirona Dental Systems, Bensheim Germany). All exposures were performed with $85 \mathrm{kV} / 10$ $\mathrm{mA}, 14 \mathrm{~S}$. Exposure protocol: Volume II to reduce image noise and patient dose. The fixed FOV was $15 \mathrm{~cm}$ $x 15 \mathrm{~cm}$ over the entire dentition with a voxel size of $0.075 \mathrm{~mm}$. All images were collected according to 
the manufacturer's instructions by an experienced radiologist. On a 17-inch display, cross-sectional pictures were collected in the axial, coronal, and sagittal planes and reconstructed.

\section{Inclusion criteria}

The inclusion criteria were as follows: evaluation of maxillary bicuspids of males and females in the UAE aged 12-70 years who provided informed consent; patients were included in the current study if they required CBCT examination for treatment planning or dental diagnosis at University Dental Hospital Sharjah, had fully developed roots, were not treated endodontically, and had no resorbed roots or calcified canals. The study excluded teeth with significant caries lesions, substantial metal restorations, fractures, orthodontic wires, veneers, teeth with immature root tips, endodontically treated teeth, and pictures with low image quality.

\section{Radiographic evaluation}

Two experienced endodontists performed all data measurements. Each investigator assessed the CBCT pictures twice and computed the average value with a two-week delay between assessments. When agreement could not be achieved, a senior oral radiologist assisted in decision-making. The following observational data were recorded during the examination of the teeth: (1) mesiodistal width of pulp chamber landmarks and morphologic measurements related to furcation, (2) number and configuration of roots, (3) number of root canals and canal configuration based on Vertucci's classification.

Teeth were radiographed in buccal and palatal views to allow direct morphological measurements related to furcation and to show cusp tips and furcation in one radiograph [24]. To reduce the possibility of perforating the furcation, the dentist should know where they are. Therefore, the most superficial landmark was selected for measurement [24-26]. A horizontal line was drawn parallel to each landmark, and six millimetre $(\mathrm{mm})$ measurements were taken from these landmark lines. First, consider the midpoint of a line that connects the two cusp points. The five measures were denoted by the letters $A, B$, $C, D$, and $E$. In detail, $A$ is the space between the lowest point on the pulp chamber roof and the highest point on the pulp chamber floor. $B$ is the space between the highest point at the pulp chamber's bottom and the highest at the root furcation. $C$ is the distance obtained by adding $A$ and $B$, i.e., the space between the lowest point on the pulp chamber ceiling and the highest position on the root furcation. $D$ is the space between the midpoint of a line connecting the two cusp points and the lowest point on the pulp chamber's ceiling. $E$ is the space between the midpoints of two cusp tips and the highest point on the root furcation (Fig. 1).

While measurements for single-rooted maxillary premolars are obtained from the lines of these landmarks, in detail, $A$ is the space between the midpoint of a line connecting the two cusp points and the lowest point on the pulp chamber's ceiling. $B$ is the space between the pulp chamber's lowest point on the ceiling and the CEJ (Fig. 2). 
According to Krasner and Rankow (2004), the dental pulp chamber's mesiodistal width in an axial view of CBCT scans was measured in an area showing the centricity of the pulp chamber at the CEJ along the horizontal plane running from mesial to distal of the pulp chamber for each upper premolar [27].

\section{Statistical analysis}

Analysis was performed using SPSS, version 26 (IBM, Armonk, NY, USA). Means (standard deviations, SD) were reported for numerical variables. Frequencies with percentages were reported for categorical variables. Pearson's Chi squared test was used to examine the association between categorical variables. Independent-sample t tests were used to compare the means of different numerical variables. Statistical significance was set at $p<0.05$.

\section{Results}

A total of 107 bilateral MFPPs with 108 bilateral MSPPs were examined. Table 1 shows that there were $52 \%$ male cases, and there were $51 \%$ cases from a local ethnic group. Table 2 shows the distribution of maxillary first and second premolar roots by gender and ethnicity. The majority of the maxillary first premolars ( $90 \%$ ) had two roots; this was observed in $92 \%$ of females, $88 \%$ of males, $83 \%$ of locals, and $96 \%$ of nonlocals. Similarly, most of the maxillary second (52\%) premolars were two roots, in $47 \%$ of females, $56 \%$ of males, $38 \%$ of locals, and $67 \%$ of nonlocals. There were only 2 cases of three roots among local males. The prevalence of one root in the maxillary second premolar was significantly higher among locals $(63 \%)$ than nonlocals (33\%). In comparison, the prevalence of two roots was higher among nonlocals $(67 \%)$ than locals $(37 \%, p=0.002)$.

Table 1

Summary of the sample with maxillary first and second premolar and gender and ethnic, $\mathrm{n}(\%)$

\begin{tabular}{|llll|}
\hline & $\begin{array}{l}\text { Bilateral maxillary first permanent } \\
\text { premolar, } \mathbf{N = 1 0 7}\end{array}$ & $\begin{array}{l}\text { Bilateral maxillary second permanent } \\
\text { premolar, N=108 }\end{array}$ & $\begin{array}{l}\text { P } \\
\text { value }\end{array}$ \\
\hline Gender & & & \\
\hline Male & $57(48.3)$ & $61(51.7)$ & 0.636 \\
\hline Female & $50(51.5)$ & $47(48.5)$ & \\
\hline Ethnicity & & & \\
\hline Local & $54(49.1)$ & $56(50.9)$ & \\
\hline $\begin{array}{l}\text { Non- } \\
\text { Local }\end{array}$ & $53(50.5)$ & $52(49.5)$ & \\
\hline
\end{tabular}


Table 2

Distribution of maxillary first and second premolar roots by gender and ethnic $(n=215), n(\%)$

\begin{tabular}{|c|c|c|c|c|}
\hline Tooth position & One root & Two roots & Three roots & P-value \\
\hline \multicolumn{5}{|l|}{ First premolars } \\
\hline Male & $5(8.8)$ & $50(87.7)$ & $2(3.5)$ & \multirow[t]{3}{*}{0.401} \\
\hline Female & $4(8)$ & $46(92)$ & 0 & \\
\hline Total & $9(8.4)$ & $96(89.7)$ & $2(1.9)$ & \\
\hline \multicolumn{5}{|c|}{ Second premolars } \\
\hline Male & $27(44.3)$ & $34(55.7)$ & 0 & \multirow[t]{3}{*}{0.357} \\
\hline Female & $25(53.2)$ & $22(46.8)$ & 0 & \\
\hline Total & $52(48.1)$ & $56(51.9)$ & 0 & \\
\hline \multicolumn{5}{|l|}{ First premolars } \\
\hline Local & $7(13)$ & $45(83.3)$ & $2(3.7)$ & \multirow[t]{3}{*}{0.076} \\
\hline Non-Local & $2(3.8)$ & $51(96.2)$ & 0 & \\
\hline Total & $9(8.4)$ & $96(89.7)$ & $2(1.9)$ & \\
\hline \multicolumn{5}{|c|}{ Second premolars } \\
\hline Local & $35(62.5)$ & $21(37.5)$ & 0 & \multirow[t]{3}{*}{0.002} \\
\hline Non-Local & $17(32.7)$ & $35(67.3)$ & 0 & \\
\hline Total & $52(48.1)$ & $56(51.9)$ & 0 & \\
\hline
\end{tabular}

Table 3: Distribution of root numbers according to tooth position (left/right) 


\begin{tabular}{|c|c|c|c|c|}
\hline Tooth position & $\begin{array}{l}\text { One root } \\
N(\%)\end{array}$ & $\begin{array}{l}\text { Two roots } \\
\mathrm{N}(\%)\end{array}$ & $\begin{array}{l}\text { Three roots } \\
\mathrm{N}(\%)\end{array}$ & P-value \\
\hline \multicolumn{5}{|l|}{ First premolars } \\
\hline Right & $4(7.5)$ & $48(90.6)$ & $1(1.9)$ & \multirow[t]{3}{*}{0.950} \\
\hline Left & $5(9.3)$ & $48(88.9)$ & $1(1.9)$ & \\
\hline Total & $9(5.3)$ & $96(89.7)$ & $2(1.9)$ & \\
\hline \multicolumn{5}{|c|}{ Second premolars } \\
\hline Right & $25(47.2)$ & $28(52.8)$ & 0 & \multirow[t]{3}{*}{0.842} \\
\hline Left & $27(49.1)$ & $28(50.9)$ & 0 & \\
\hline Total & $52(48.1)$ & 56 (51.9) & 0 & \\
\hline
\end{tabular}

Table 4: Frequency distribution of the number of the roots and canals of maxillary premolars in a group of UAE population, $n(\%)$

\begin{tabular}{|c|c|c|c|c|c|c|}
\hline & \multicolumn{3}{|l|}{ Local UAE } & \multicolumn{3}{|c|}{ Non-local UAE (South Asian) } \\
\hline & $\begin{array}{l}\text { Maxillary first } \\
\text { premolar } \\
(n=54)\end{array}$ & $\begin{array}{l}\text { Maxillary } \\
\text { second } \\
\text { premolar }(n=56)\end{array}$ & $\begin{array}{l}P \\
\text { value }\end{array}$ & $\begin{array}{l}\text { Maxillary } \\
\text { first premolar } \\
(n=53)\end{array}$ & $\begin{array}{l}\text { Maxillary } \\
\text { second } \\
\text { premolar } \\
(n=52)\end{array}$ & $\begin{array}{l}P \\
\text { value }\end{array}$ \\
\hline \multicolumn{7}{|c|}{$\begin{array}{l}\text { Number } \\
\text { of roots }\end{array}$} \\
\hline One & $7(16.7)$ & $35(83.3)$ & $\begin{array}{l}< \\
0.0001\end{array}$ & $2(10.5)$ & $17(89.5)$ & $<.0001$ \\
\hline Two & $45(68.2)$ & $21(31.8)$ & & $51(59.3)$ & $35(40.7)$ & \\
\hline Three & $2(100)$ & 0 & & 0 & 0 & \\
\hline \multicolumn{7}{|c|}{$\begin{array}{l}\text { Number } \\
\text { of } \\
\text { canals }\end{array}$} \\
\hline One & 0 & $1(100)$ & 0.218 & 0 & 0 & $\mathrm{n} / \mathrm{a}$ \\
\hline Two & $52(48.6)$ & $55(51.4)$ & & $53(50.5)$ & $52(49.5)$ & \\
\hline Three & $2(100)$ & 0 & & 0 & 0 & \\
\hline
\end{tabular}

Table 3 shows no significant differences in the number of roots distributed according to tooth position (left/right for first and second premolars, $p>0.05$ ). 
A total of 54 maxillary first premolars and 56 maxillary second premolars in the local UAE population and 53 maxillary first premolars and 52 maxillary second premolars in the nonlocal UAE population were analysed, and the number of roots, root canals, and type of canal configurations were evaluated. The results are presented in Tables $4 \& 5$.

Table 4 shows that one root in a maxillary first premolar was detected in $17 \%$ of local UAE subjects and $11 \%$ of nonlocal UAE subjects and two roots maxillary first premolar in $68 \%$ of local UAE and $59 \%$ of nonlocal UAE $(p<0.0001)$. Found three roots only in 2 teeth in the first premolar. Almost all local and nonlocal groups had two canals for both the first and second maxillary premolars.

Found one root of maxillary second premolar in $83 \%$ of local UAE subjects and $90 \%$ of nonlocal UAE subjects, and two roots of the maxillary second premolar were found in $32 \%$ of local UAE subjects and $41 \%$ of nonlocal UAE subjects (Table 4 ).

Table 5 shows the distribution of different canal morphologies in maxillary premolars. Based on the Vertucci classification, the most common canal morphology in the maxillary first premolar group among local UAE, was type V (52\%), followed by type IV (26\%) and type II (6\%). An additional type, 2 (3.7\%), was also identified and is not related to the Vertucci classification.

The dominant canal morphology in the maxillary second premolar group among local UAE subjects was type II (32\%), followed by type III (27\%) and type V (20\%).

Based on the Vertucci classification, the most common canal morphology in the maxillary first premolar group among nonlocal UAE subjects was type V (59\%), followed by type IV (9\%) and type VI (8\%). An additional type, 7 (13.2\%), was also identified and unrelated to the Vertucci classification.

In the maxillary second premolar group among nonlocal UAE subjects, the dominant canal morphology was type V (25\%), followed by type III (15.4\%) and type VII (13.5\%). Based on the Vertucci classification, an additional type, 12 (23.1\%), was also identified and not related to the Vertucci classification.

Table 6 shows a comparison of various morphological measurements recorded from single-rooted maxillary premolar CBCT. There was a statistically significant difference in the distance from the mesial to the distal pulp chamber in the single-rooted maxillary premolar CBCTs between the local UAE $(1.26 \pm$ $0.27 \mathrm{~mm})$ and South Asian population $(1.10 \pm 0.32 \mathrm{~mm}, \mathrm{p}=0.037)$.

There was no statistically significant difference in the distance from the midpoint of a line connecting the two cusp tips to the lowest point on the roof of the pulp chamber in single-rooted maxillary premolar CBCTs for the local UAE population $(5.58 \pm 0.72 \mathrm{~mm})$ and South Asian population $(5.31 \pm 1.08 \mathrm{~mm}, \mathrm{p}=$ $0.252)$.

There was a significant difference between the distance from the lowest point on the pulp chamber roof to the CEJ in the single-rooted maxillary premolar CBCT for local UAE subjects $(1.36 \pm 0.75 \mathrm{~mm})$ and South Asian subjects $(1 \pm 0.27 \mathrm{~mm}, \mathrm{p}=0.049)$. 
Table 7 shows a comparison of various morphological measurements recorded from multiple rooted maxillary premolars in CBCTs. There were statistically significant differences in all measurements in multiple rooted maxillary premolar CBCT between the local UAE and South Asian population ( $p$ value $<0.05)$.

Table 5: Root canal morphology of the maxillary premolars of UAE population, $n$ (\%)

\begin{tabular}{|lllll|}
\hline & Local UAE & & \multicolumn{2}{l|}{ Non-local UAE (South Asian) } \\
\hline $\begin{array}{l}\text { Canal } \\
\text { morphology }\end{array}$ & $\begin{array}{l}\text { Maxillary first } \\
\text { Premolar }\end{array}$ & $\begin{array}{l}\text { Maxillary second } \\
\text { Premolar }\end{array}$ & $\begin{array}{l}\text { Maxillary first } \\
\text { Premolar }\end{array}$ & $\begin{array}{l}\text { Maxillary second } \\
\text { Premolar }\end{array}$ \\
\hline Type I & $1(1.9)$ & $1(1.8)$ & $1(1.9)$ & 0 \\
\hline Type II & $3(5.6)$ & $18(32.1)$ & $1(1.9)$ & $4(7.7)$ \\
\hline Type III & $3(5.6)$ & $15(26.8)$ & 0 & $8(15.4)$ \\
\hline Type IV & $14(25.9)$ & $6(10.7)$ & $5(9.4)$ & $3(5.8)$ \\
\hline Type V & $28(51.9)$ & $11(19.6)$ & $31(58.5)$ & $13(25)$ \\
\hline Type VI & $2(3.7)$ & $4(7.1)$ & $4(7.5)$ & $5(9.6)$ \\
\hline Type VII & $1(1.9)$ & $1(1.8)$ & $4(7.5)$ & $7(13.5)$ \\
\hline Others & $2(3.7)$ & 0 & $7(13.2)$ & $12(23.1)$ \\
\hline Total & $54(100)$ & $56(100)$ & $53(100)$ & $52(100)$ \\
\hline
\end{tabular}

Table 6: Comparison of various morphological measurements recorded from single-rooted maxillary premolars $\mathrm{CBCT}$ 


\begin{tabular}{|c|c|c|c|c|c|}
\hline \multirow[t]{2}{*}{ Distances } & $\begin{array}{l}\text { Single } \\
\text { rooted } \\
\text { maxillary } \\
\text { premolars }\end{array}$ & $\begin{array}{l}\text { Single } \\
\text { rooted } \\
\text { maxillary } \\
\text { premolars }\end{array}$ & $\begin{array}{l}\text { Mean } \\
\text { difference }\end{array}$ & $\begin{array}{l}\mathrm{t} \\
\text { statistic }\end{array}$ & $\begin{array}{l}\mathrm{P} \text { - } \\
\text { value }\end{array}$ \\
\hline & $\begin{array}{l}\text { CBCT for } \\
\text { local UAE, } \\
\text { mean (SD) }\end{array}$ & $\begin{array}{l}\text { CBCT for } \\
\text { non-local, } \\
\text { mean (SD) }\end{array}$ & & & \\
\hline $\begin{array}{l}\text { Distance from mesial to distal of } \\
\text { the pulp chamber }\end{array}$ & $1.26(0.27)$ & $1.10(0.32)$ & 0.17 & 2.14 & 0.037 \\
\hline $\begin{array}{l}\text { Distance from the middle of a line } \\
\text { connecting the two cusp tips to the } \\
\text { lowest point on the pulp chamber } \\
\text { roof. }\end{array}$ & $5.58(0.72)$ & $5.31(1.08)$ & 0.27 & 1.16 & 0.252 \\
\hline $\begin{array}{l}\text { Distance from the lowest point on } \\
\text { the roof of the pulp chamber to the } \\
\text { CEJ. }\end{array}$ & $1.36(0.75)$ & $1(0.27)$ & 0.36 & 2.01 & 0.049 \\
\hline
\end{tabular}


Table 7

Comparison of various morphological measurements recorded from multiple rooted maxillary premolars CBCT

\begin{tabular}{|c|c|c|c|c|c|}
\hline \multirow[t]{2}{*}{ Distances } & $\begin{array}{l}\text { multiple } \\
\text { rooted } \\
\text { maxillary } \\
\text { premolars }\end{array}$ & $\begin{array}{l}\text { multiple } \\
\text { rooted } \\
\text { maxillary } \\
\text { premolars }\end{array}$ & $\begin{array}{l}\text { Mean } \\
\text { difference }\end{array}$ & $\begin{array}{l}\mathrm{t} \\
\text { statistic }\end{array}$ & \multirow[t]{2}{*}{$\begin{array}{l}P- \\
\text { value }\end{array}$} \\
\hline & $\begin{array}{l}\text { CBCT for } \\
\text { local UAE } \\
\text { (mean } \pm \\
\text { SD) }\end{array}$ & $\begin{array}{l}\text { CBCT for } \\
\text { South Asian } \\
\text { (mean } \pm \\
\text { SD) }\end{array}$ & & & \\
\hline $\begin{array}{l}\text { Distance from mesial to distal of } \\
\text { the pulp chamber }\end{array}$ & $1.21(0.27)$ & $1.06(0.25)$ & 0.16 & 3.66 & $\begin{array}{l}< \\
0.0001\end{array}$ \\
\hline $\begin{array}{l}\text { Distance from the lowest point on } \\
\text { the pulp chamber roof to the } \\
\text { highest point on the pulp chamber } \\
\text { floor. }\end{array}$ & $2.57(0.88)$ & $2.24(0.78)$ & 0.33 & 2.47 & 0.015 \\
\hline $\begin{array}{l}\text { Distance from highest point on } \\
\text { floor of the pulp chamber to the } \\
\text { highest point on the root furcation. }\end{array}$ & $2(0.74)$ & $1.31(0.49)$ & 0.45 & 7.14 & $\begin{array}{l}< \\
0.0001\end{array}$ \\
\hline $\begin{array}{l}\text { Distance from the lowest point on } \\
\text { the pulp chamber roof to the } \\
\text { highest point on the root furcation. }\end{array}$ & $4.57(1.05)$ & $3.55(1.01)$ & 1.02 & 6.11 & $\begin{array}{l}< \\
0.0001\end{array}$ \\
\hline $\begin{array}{l}\text { Distances from the midpoint of a } \\
\text { line connecting the two cusp tips } \\
\text { to the lowest point on the pulp } \\
\text { chamber roof. }\end{array}$ & $6.11(0.99)$ & $5.75(0.90)$ & 0.35 & 2.34 & 0.020 \\
\hline $\begin{array}{l}\text { Distances from the midpoint of a } \\
\text { line connecting the two cusp tips } \\
\text { to the highest point on the root } \\
\text { furcation. }\end{array}$ & $10.83(1.33)$ & $9.77(1.24)$ & 1.06 & 5.09 & $<.0001$ \\
\hline
\end{tabular}

\section{Discussion}

Endodontic procedures are standard challenging procedures in daily dental practice. Therefore, an understanding of root canal anatomy is required for a successful RCT. However, tooth anatomy varies between persons and between populations. The most variation in anatomical structures was seen in maxillary first and second bicuspid teeth [11].

The majority of the problems encountered while treating the root canal were seen in maxillary premolars owing to variations in the architecture of the root canal systems; thus, maxillary premolars were selected for the current research. 
To our knowledge, this is the first study to investigate the root and canal morphologies and symmetry of each maxillary first and second premolar simultaneously in a UAE population using a pattern of CBCT images. We hoped that our research would assist in improving effective root canal treatment in the UAE and contribute to the literature on root canal morphology and symmetry of permanent teeth in the South Asian population.

The bulk of anatomic investigations discovered that the most common type of maxillary first premolar is the two-rooted form, and the incidence of three-rooted forms is rare $[7,17,22,28-37]$.

In the current study, $90 \%$ of the maxillary first premolars supplied roots, indicating that the two-root shape was the most common root anatomy in a UAE population (Table 2). This rate was similar to that reported by Neelakantan, who discovered that $86 \%$ of the teeth in a mostly Indian population had two roots [29]. In comparison, the result was significantly higher than in Saudi Arabia in 2008 (80.9\%) [30], Brazil (80.2\%) [31], Saudi (2013 71.7\%) [32], Kosovar (70.14\%) [33], Turkish (70.8\%) [34], Jordanian [35] and Pakistani [36] (68.6\%), German [37] and Israeli [22] (62\%), Saudi 2019 [17] and Turkish (1998, 61\%) [7] populations. Single-rooted teeth were less common (8\%), ranging from $11.7-37.3 \%[17,22,29-37]$. Three-rooted maxillary first premolars were found in just two of 107 maxillary first premolar teeth, representing a low frequency of $1.9 \%$ (Table 2). Three-rooted maxillary first premolars are uncommon in general [8]. Despite the modest number of three-rooted first premolars, clinicians must not ignore the third root and its internal canal.

According to Ingle, most anatomic investigations have shown that the most common type of maxillary second premolar is the single-rooted form, with the frequency of three-rooted forms ranging from $0-1 \%$. The number of two-rooted maxillary second premolars ranged from 1.6-20.4\% [28].

When compared to work by Ingle, research by others shows that the maxillary second premolar has a greater incidence of two rooted maxillary second premolars among the Jordanian population (about 44.2\%) [18], the Turkish [7] and Saudi population (30\%) [38], the Brazilian population (28\%) [31], and the Saudi population (23.6\%) [32].

Most of the teeth studied in this research (52\%) had two roots, whereas the remaining teeth (48\%) had a single root. The proportion of two-rooted teeth was greater than in prior research with other groups $[7,18$, $31,32,38]$. These differences emphasise the impact of ethnic background, evaluation techniques, and sample sizes on root morphology studies in maxillary premolars.

Root canal configurations vary from teeth to teeth and from population to population. In our study, almost all local and nonlocal populations had two canals in both the first and second maxillary premolars (Table 4). This share lies within the range mentioned in research on the usage of CBCT or clearing techniques $[7,8,19,23,29,36,38-40]$. Only two maxillary first premolars $(0.2 \%)$ had the threecanal morphology within the previously described range of $0.4-3.3 \%$. [4, 7, 23, 35, 41, 42]. Vertucci (1984) found that the maxillary first premolar was the only tooth with all eight kinds of canal morphology [9]. The current investigation confirmed that root canal networks have a wide range of structural diversity. In 
addition, six types of uncommon canal anatomic variants (types 1-2-3, 2-3-2, 3-2-1, 1-2-3-2, 2-1-2-1, and 32) were discovered in both maxillary first and second premolars. According to Sert and Bayirli's classification of canal configurations [43], type 2-1-2-1 was designated as type XIX (Fig. 3), type 3-2 as type XV, type 1-2-3-2 as type $X$, type 2-3-2 and type 3-2-1 as a new type.

Similar to this research, several published investigations have identified these kinds of canals in maxillary bicuspids. Yi-Han Li, Mutasim, and Jayasimha reported type XIX canal configurations [14, 23, 38]. Mutasim and Senan reported type 1-2-3, type 3-2-1, type 2-3-2 and type 3-2 canal configurations [19, 38]. The current study's most interesting findings were the new root canal types discovered in $3.7 \%$ of local UAE subjects and $36.3 \%$ of nonlocal UAE subjects. These canal types account for a sizable proportion of the total. As a result, it is necessary to assume that therapy will be difficult. Type $\mathrm{V}(52 \%)$ was the most common canal configuration in maxillary first premolars among local UAE subjects, whereas type II (32\%) was the most common canal configuration in second premolars. Moreover, type $\mathrm{V}$ (59\%) was the most common canal configuration in maxillary first premolars among nonlocal UAE residents, and type $\mathrm{V}$ $(25 \%)$ was the most common canal configuration in second premolars. This finding is consistent with previous findings $[3,14,29,37,38,44,45]$.

Understanding pulp chamber morphological measurements is important for proper access for successful endodontic treatment and the avoidance of errors such as perforation while locating the canals.

The anatomical landmark associated with the pulp chamber of maxillary furcated bicuspids was measured for the first time in Deutsch's study [24]. Then, in 2007, Venkateshbabu et al. observed that the morphological measurement of maxillary first premolars in the Indian population was equivalent to a previous study [25]. In the Nagpur population, however, these furcated bicuspid teeth were observed to be significantly longer. In maxillary first premolars, the author observed that the CEJ corresponds to the ceiling of the pulp chamber, which is identical to the pulp chamber discovered by Deutsch $[24,26]$.

The distance between the midpoint of a line connecting the two cusp points and the furcation, according to Deutsch and Musikant (2005), is $11.55 \mathrm{~mm}$ [24]. The height of the pulp chamber is $2.76 \mathrm{~mm}$, and the average distance between the midpoint of a line joining the two cusp suggestions and the roof of the pulp chamber is $6.94 \mathrm{~mm}$. The authors found that the CEJ was constantly near the pulp chamber ceiling of the top furcated bicuspids.

The distance between the midpoint of a line connecting the two cusp points and the closest point to the furcation was $10.83 \pm 1.33 \mathrm{~mm}$ in the local UAE population and $9.77 \pm 1.24 \mathrm{~mm}$ in the nonlocal UAE population in our research. For maxillary second premolars, the average distance between the midpoint of a line connecting the two cusps and the ceiling of the pulp chamber was $6.11 \pm 0.99 \mathrm{~mm}$ for local UAE subjects and $5.75 \pm 0.90 \mathrm{~mm}$ for nonlocal UAE subjects. For maxillary first premolars, the mean distance between the midpoint of a line connecting the two cusps and the ceiling of the pulp chamber was $5.58 \pm$ $0.72 \mathrm{~mm}$ for the local UAE population and $5.31 \pm 1.08 \mathrm{~mm}$ for the nonlocal UAE population. The height of the pulp chamber was $2.57 \pm 0.88 \mathrm{~mm}$ for local UAE subjects and $2.24 \mathrm{~mm} \pm 0.78 \mathrm{~mm}$ for nonlocal UAE subjects. 
Clinically, approximately $4.6 \mathrm{~mm}$ is available to perforate after reaching the pulp chamber's roof (at the level of the CEJ). The addition of this distance to the $6.1 \mathrm{~mm}$ distance between the cusp tip and the pulp chamber ceiling for bicuspids yields $10.7 \mathrm{~mm}$, approximately $11 \mathrm{~mm}$. A drill should be marked at $11 \mathrm{~mm}$, so the dentist understands where it is in the furcation to decrease the possibility of perforation in the furcation. These results were similar to those of Deutsch's study.

As each year of life progressed, the size of the pulp chamber decreased due to calcification. Therefore, these measurements differed in ways that were either directly or indirectly related to the height of the pulp chamber.

\section{Conclusions}

Our study is the first to analyse the most common morphology of the upper premolars in a group of Emirati subpopulations. The results in the current study serve as a guide that can offer a more quantitative approach to maxillary first and second premolars to access cavity preparation in the UAE population to prevent errors and iatrogenic damage when identifying the canals; CBCT measurements can be advantageous for more precise access preparations.

\section{Abbreviations}

UAE: United Arab Emirates; CBCT: Cone Beam Computed Tomography; 3D: Three Dimension; SD: Standard Deviations; SPSS: Statistical Package for the Social Sciences; RCT: Root canal treatment; CEJ: Cementoenamel Junction; MFPP: Maxillary First Permanent Premolar; MSPP: Maxillary Second Permanent Premolar; FOV: Field of View; UDHS: University Dental Hospital Sharjah.

\section{Declarations}

\section{Ethics approval and consent to participate}

The Local Research Ethics Committee approved this study without restrictions under the protocol number: REC-20-03-03-01-S. Through this approval, the research team had the required administrative permissions to access the data used in this research. For this type of retrospective study, and as recommended by the Research and Ethics Committee, formal consent is not required.

\section{Consent for publication}

Not applicable

\section{Availability of data and materials}

The datasets used and analysed during the current study are available from the corresponding author on reasonable request. 


\section{Competing interests}

The authors declare that they have no competing interests.

\section{Funding}

This study received no study from profit or not-for-profit organizations.

\section{Authors' contributions}

H.A, Conceptualization, Methodology, Investigation, Data curation, Writing Original Draft; MG, Supervision, Investigation, Reviewing and Editing; SA, Methodology, Investigation, Reviewing and Editing; SWA, Supervision, Methodology, Data curation; IM, Supervision, Methodology, Data curation, Formal Analysis, Reviewing and Editing. The authors read and approved the final manuscript

\section{Acknowledgements}

The authors are grateful to the study participants.

\section{References}

1. Löst, C. Quality guidelines for endodontic treatment: consensus report of the European Society of Endodontology Int Endod J. 2006; doi:10.1111/j.1365-2591.2006.01180. x.

2. Iqbal A. The factors responsible for endodontic treatment failure in the permanent dentitions of the patients reported to the college of dentistry, the university of Aljouf, Kingdom of Saudi Arabia. J Clin Diagnostic Res. 2016; doi:10.7860/JCDR/2016/14272.7884.

3. Vertucci FJ. Root canal morphology and its relationship to endodontic procedures. J Endod Top. 2005; doi:10.1111/j.1601-1546.2005. 00129.x.

4. Tian YY, Guo B, Zhang R, Yu X, Wang H, Hu T, et al. Root and canal morphology of maxillary first premolars in a Chinese subpopulation evaluated using cone-beam computed tomography. Int Endod J. 2012; doi:10.1111/j.1365-2591.2012.02059x.

5. Estrela C, Holland R, de Araújo Estrela CR, Alencar AHG, Sousa-Neto MD, Pécora JD. Characterization of successful root canal treatment. Braz Dent J. 2014; doi:10.1590/0103-6440201302356

6. Krapež J, Fidler A. Location and dimensions of access cavity in permanent incisors, canines, and premolars. J Conserv Dent. 2013; doi:10.4103/0972-0707.117491.

7. Kartal N. Root canal morphology of maxillary premolars. J Endod. 1998; doi:10.1016/S00992399(98)80024-1.

8. Abella F, Teixidó LM, Patel S, Sosa F, Duran-Sindreu F, Roig M. Cone-beam Computed Tomography Analysis of the Root Canal Morphology of Maxillary First and Second Premolars in a Spanish Population. J Endod. 2015; doi:10.1016/jjoen.2015.03.026. 
9. Vertucci FJ. Root canal anatomy of the human permanent teeth. Oral Surgery, Oral Med Oral Pathol. 1984; doi:10.1016/0030-4220(84)90085-9.

10. Asheghi B, Momtahan N, Sahebi S, Zangoie Booshehri M. Morphological Evaluation of Maxillary Premolar Canals in Iranian Population: A Cone-Beam Computed Tomography Study. J Dent. 2020; doi:10.30476/DENTJODS.2020.82299.1011

11. Liu X, Gao M, Ruan J, Lu Q. Root Canal Anatomy of Maxillary First Premolar by Microscopic Computed Tomography in a Chinese Adolescent Subpopulation. Biomed Res Int. 2019; doi:10.1155/2019/4327046.

12. Cleghorn BM, Christie WH, Dong CCS. Root and Root Canal Morphology of the Human Permanent Maxillary First Molar: A Literature Review. J Endod. 2006; doi:10.1016/jjoen.2006.04.014.

13. Ahmad IA, Alenezi MA. Root and Root Canal Morphology of Maxillary First Premolars: A Literature Review and Clinical Considerations. Journal of Endodontics. 2016; doi:10.1016/jjoen.2016.02.017.

14. Jayasimha R, Mylswamy S. Root canal morphology of maxillary second premolars in an Indian population. J Conserv Dent. 2010; doi:10.4103/0972-0707.71648

15. Cohen S, Burns RC. Pathways of the Pulp. 5th ed. St. Louis: Mosby; 2002. p. 173-228.).

16. Bansal R, Hegde S, Astekar MS. Classification of Root Canal Configurations: A Review and a New Proposal of Nomenclature System for Root Canal Configuration. J Clin DIAGNOSTIC Res. 2018; doi: $10.7860 / \mathrm{jcdr} / 2018 / 35023.11615$

17. Maghfuri S, Keylani H, Chohan H, Dakkam S, Atiah A, Mashyakhy M. Evaluation of root canal morphology of maxillary first premolars by cone beam computed tomography in Saudi Arabian southern region subpopulation: An in vitro study. Int J Dent. 2019; doi:10.1155/2019/2063943

18. Al-Ghananeem MMF, Haddadin K, Al-Khreisat AS, Al-Weshah M, Al-Habahbeh N. The number of roots and canals in the maxillary second premolars in a group of Jordanian population. International Journal of Dentistry. 2014; doi:10.1155/2014/797692.

19. Senan EM, Alhadainy HA, Genaid TM, Madfa AA. Root form and canal morphology of maxillary first premolars of a Yemeni population. BMC Oral Health. 2018; doi:10.1186/s12903-018-0555-x.

20. Bueno MR, Estrela CRA, Granjeiro JM, Sousa-Neto MD, Estrela C. Method to determine the root canal anatomic dimension by using a new cone-beam computed tomography software. Braz Dent J. 2019; doi:10.1590/0103-6440201902462

21. Fayad MI, Nair M, Levin MD, Benavides E, Rubinstein RA, Barghan S, et al. AAE and AAOMR Joint Position Statement. Oral Surg Oral Med Oral Pathol Oral Radiol J 2015; doi:

10.1016/j.joen.2015.07.013

22. Kfir A, Mostinsky O, Elyzur O, Hertzeanu M, Metzger Z, Pawar AM. Root canal configuration and root wall thickness of first maxillary premolars in an Israeli population. A Cone-beam computed tomography study. Sci Rep. 2020; doi:10.1038/s41598-019-56957-z.

23. Li Y han, Bao S jie, Yang X wen, Tian X mei, Wei B, Zheng Y li. Symmetry of root anatomy and root canal morphology in maxillary premolars analyzed using cone-beam computed tomography. Arch Oral Biol. 2018; doi:10.1016/jarchoralbio.2018.06.020 
24. Deutsch AS, Musikant BL, Gu S, Isidro M. Morphological measurements of anatomic landmarks in pulp chambers of human maxillary furcated bicuspids. J Endod. 2005; doi:

10.1097/01.don.0000152299.78668.7c.

25. Venkateshbabu N, Velmurugan N, Roy A, Kandaswamy D. Evaluation of the pulp chamber morphological measurements in maxillary first premolar in Indian population - an in-vitro study. $J$ Conserv Dent. 2007; doi:10.4103/0972-0707.43030

26. Shravan et al. Evaluation of the Pulp Chamber Morphological. Measurements in Maxillary First Premolar: A Cone Beam Volumetric Analysis. Heal Talk J. 2014; doi:10.1143-1412843115

27. Krasner P, Rankow HJ. Anatomy of the pulp-chamber floor. J Endod. 2004; doi:10.1097/00004770200401000-00002.

28. Rotstein I, Ingle JI. Ingle's Endodontics. Stamford: PMPH-USA; 2019.

29. Neelakantan P, Subbarao C, Ahuja R, Subbarao CV. Root and canal morphology of Indian maxillary premolars by a modified root canal staining technique. Odontology. 2011; doi:10.1007/s10266-0100137-0.

30. Atieh MA. Root and canal morphology of maxillary first premolars in a Saudi population. J Contemp Dent Pract. 2008; doi:10.5005/jcdp-9-1-46

31. de Lima CO, de Souza LC, Devito KL, do Prado M, Campos CN. Evaluation of root canal morphology of maxillary premolars: a cone-beam computed tomography study. Aust Endod J. 2019; doi:10.1111/aej.12308

32. Elkady A, Allouba K. Cone beam computed tomographic analysis of root and canal morphology of maxillary premolars in Saudi subpopulation. Egypt Dent J. 2013; 59 3419-3429

33. Koçani F, Kamberi B, Dragusha E, Kelmendi T, Sejfija Z. Correlation between Anatomy and Root Canal Topography of First Maxillary Premolar on Kosovar Population. Open J Stomatol. 2014; doi:10.4236/ojst.2014.47046.

34. Bulut DG, Kose E, Ozcan G, Sekerci AE, Canger EM, Sisman Y. Evaluation of root morphology and root canal configuration of premolars in the Turkish individuals using cone beam computed tomography. Eur J Dent. 2015; doi:10.4103/1305-7456.172624

35. Awawdeh L, Abdullah H, Al-Qudah A. Root Form and Canal Morphology of Jordanian Maxillary First Premolars. J Endod. 2008; doi: 10.1016/j.joen.2008.04.013

36. Nazeer MR, Khan FR, Ghafoor R. Evaluation of root morphology and canal configuration of maxillary premolars in a sample of Pakistani population by using cone beam computed tomography. J Pak Med Assoc. 2018; 68(3), 423-427.

37. Bürklein S, Heck R, Schäfer E. Evaluation of the Root Canal Anatomy of Maxillary and Mandibular Premolars in a Selected German Population Using Cone-beam Computed Tomographic Data. J Endod. 2017; doi: 10.1016/j.joen.2017.03.044.

38. Elnour M, Khabeer A, AlShwaimi E. Evaluation of root canal morphology of maxillary second premolars in a Saudi Arabian sub-population: An in vitro microcomputed tomography study. Saudi Dent J. 2016; doi: 10.1016/j.sdentj.2016.08.001. 
39. Yang L, Chen X, Tian C, Han T, Wang Y. Use of Cone-beam Computed Tomography to Evaluate Root Canal Morphology and Locate Root Canal Orifices of Maxillary Second Premolars in a Chinese Subpopulation. J Endod. 2014; doi: 10.1016/j.joen.2014.01.007

40. Al-Nazhan S, Al-Daafas A, Al-Maflehi N. Radiographic investigation of in vivo endodontically treated maxillary premolars in a Saudi Arabian sub-population. Saudi Endod J. 2012; doi:10.4103/16585984.104407.

41. Chaparro AJ, Segura JJ, Guerrero E, Jiménez-Rubio A, Murillo C, Feito JJ. Number of roots and canals in maxillary first premolars: Study of an Andalusian population. Dent Traumatol. 1999; doi:10.1111/j.1600-96571999.tb00755.x

42. Gupta S, Sinha DJ, Gowhar O, Tyagi SP, Singh NN, Gupta S. Root and canal morphology of maxillary first premolar teeth in north Indian population using clearing technique: An in vitro study. J Conserv Dent. 2015; doi:10.4103/0972-0707.157260

43. Sert S, Bayirli GS. Evaluation of the root canal configurations of the mandibular and maxillary permanent teeth by gender in the Turkish population. J Endod. 2004; doi:10.1097/00004770200406000-00004

44. Nikkerdar N, Asnaashari M, Karimi A, Araghi S, Seifitabar S, Golshah A. Root and canal morphology of maxillary teeth in an Iranian subpopulation residing in western Iran using cone-beam computed tomography. Iran Endod J. 2020; doi:10.22037/iej. v15i1.25386.

45. Weng XL, Yu S Bin, Zhao SL, Wang HG, Mu T, Tang RY, et al. Root Canal Morphology of Permanent Maxillary Teeth in the Han Nationality in Chinese Guanzhong Area: A New Modified Root Canal Staining Technique. J Endod. 2009; doi: 10.1016/j.joen.2009.02.01

\section{Figures}




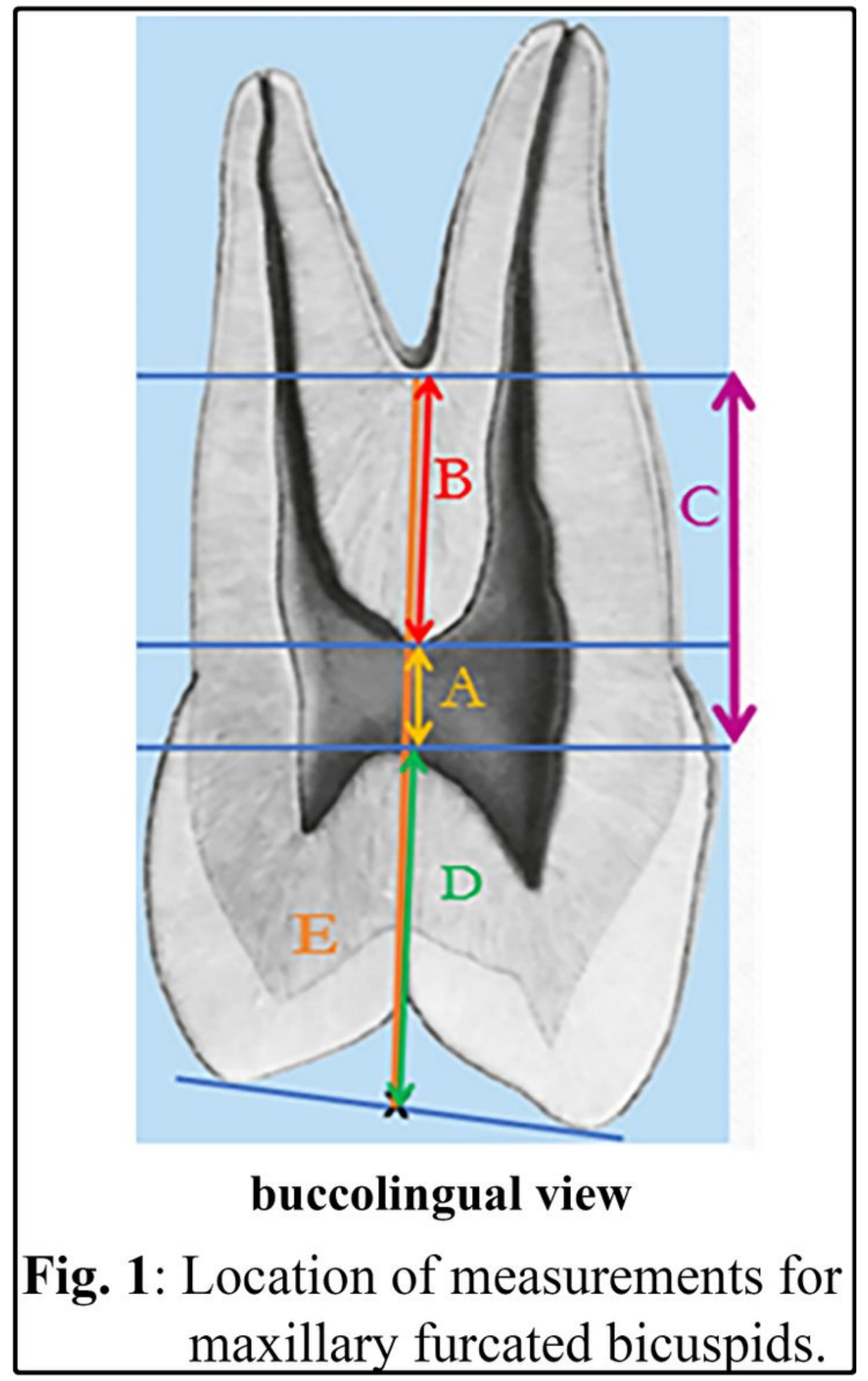

Figure 1

See image above for figure legend 

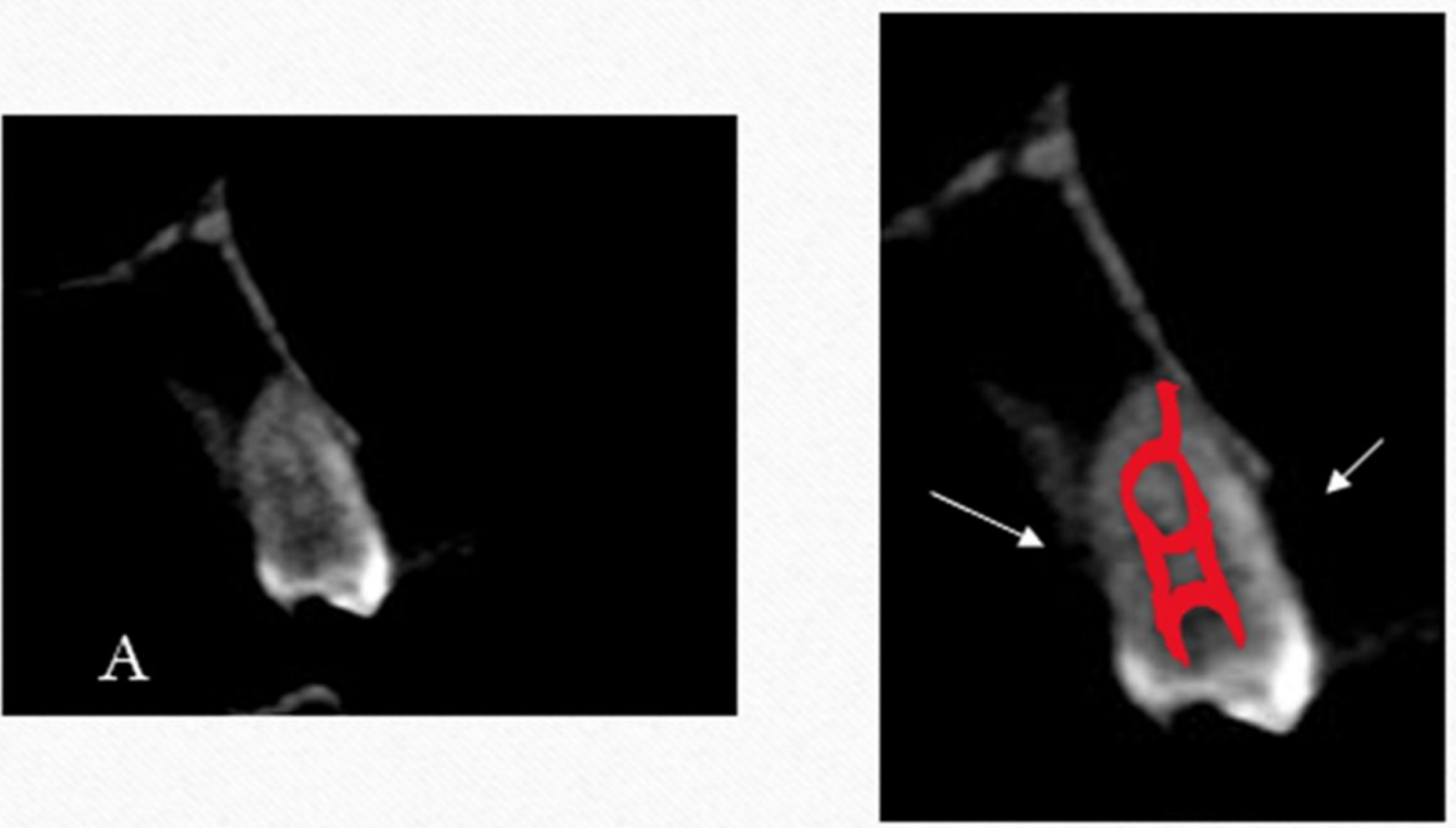

Fig. 3: (A) Cross-section CBCT images showing one rooted maxillary second premolar (arrow) showing 2121 canal configuration maxillary second premolar. (canal configuration not related to Verrtuci classification)

Figure 2

See image above for figure legend 


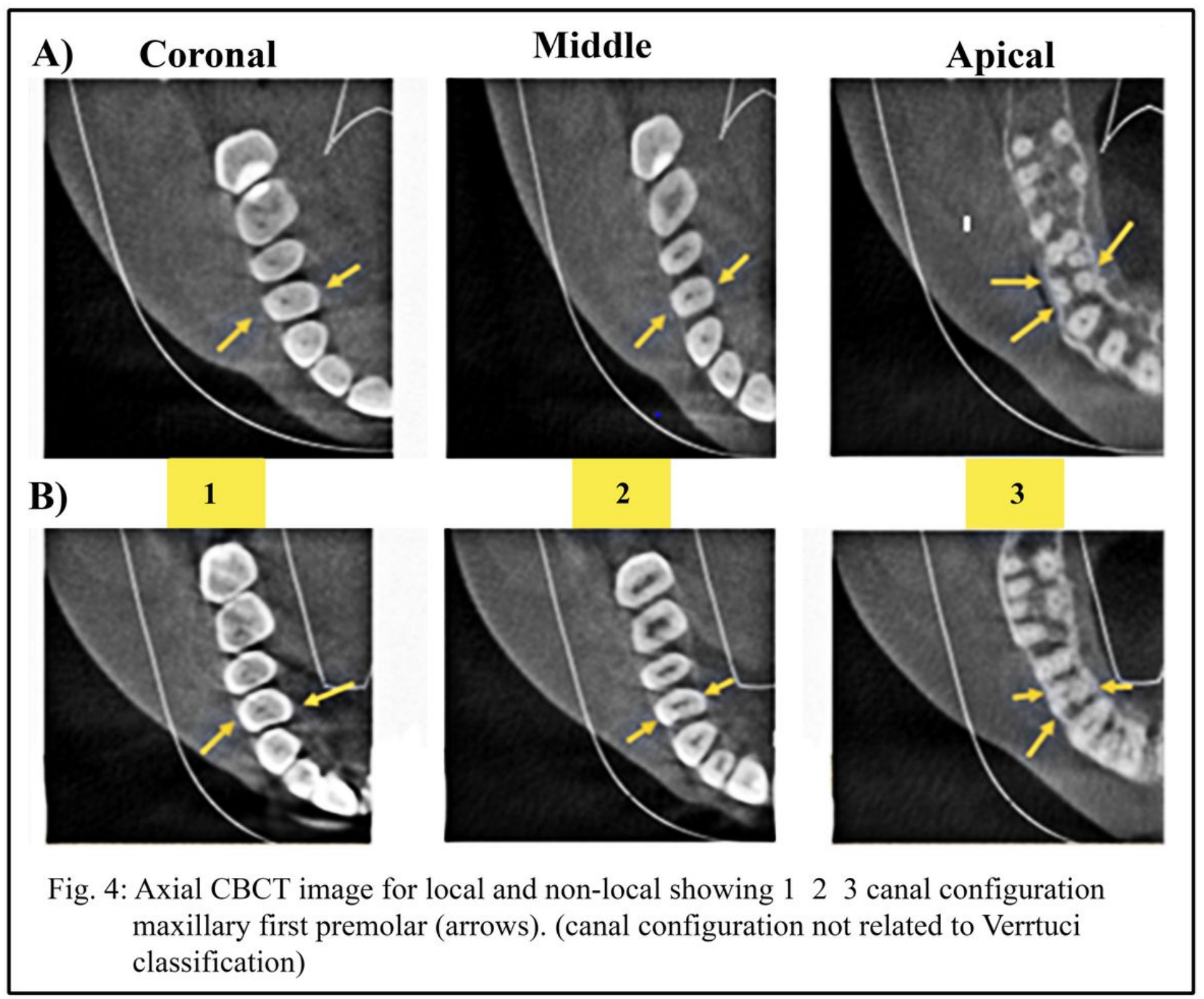

Figure 3

See image above for figure legend 


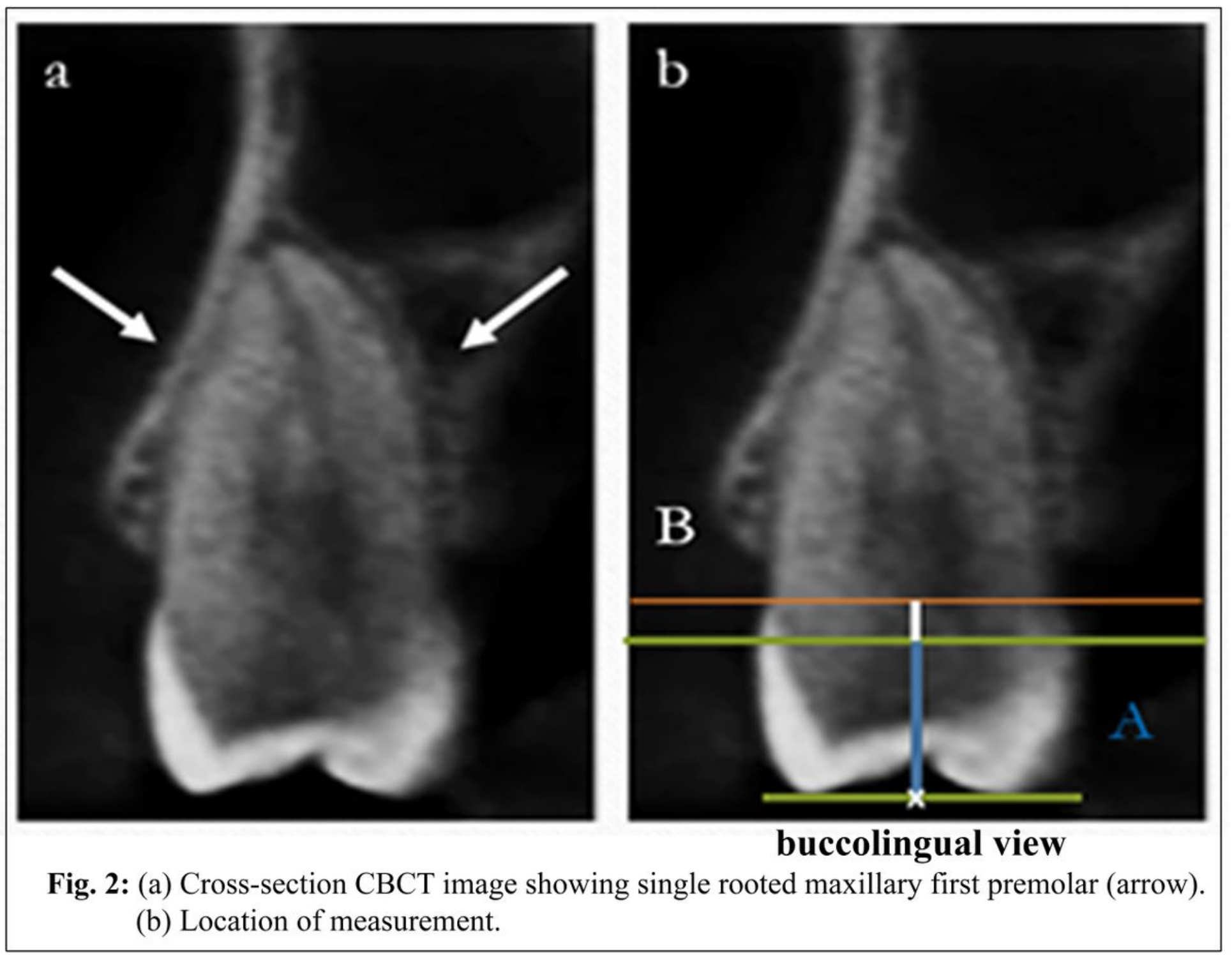

Figure 4

See image above for figure legend 